\title{
XIVth INTERNATIONAL OPHTHALMIC CONGRESS
}

\section{Communication from the International Ophthalmological Council}

\section{MADRID CONGRESS, 1933}

I. The XIVth International Ophthalmological Congress will take place in Madrid at the beginning of April, 1933. The principal subjects to be discussed at this congress, are

(a) Tuberculosis of the Iris and Ciliary Body.

\section{Reporters}

Address

Dr. E. V. L. Brown - University of Chicago, 950 E. 59th Street, Chicago III. (U.S.A.)

Prof. Dr. J. Igers- Brentanostrasse 1, heimer

Frankfort a. Main, Germany

Dr. Henri Lagrange - 5, Avenue Daniël Lesueur, Diagnosis and Paris, VII, France

(b) Detachment of Retina.

\author{
Subdivision of \\ subject
}

Modern methods of treatment

Pathological anatomy differential diagnosis 
of the secretary of the Internat. Ophthalm. Council on December 1, 1932, at the latest.

In order to secure the best selection from all papers sent in, an international committee of ophthalmologists shall previously examine all communications. After that, authors of communications will be informed if their papers are to be accepted for reading or not.

III. With regard to reports, drawn up for the XIIIth Internat. Ophthalm. Congress at the request of the Internat. Ophthalm. Council, the complete commission of reporters shall take their final decisions during the XIVth Congress. These decisions shall be communicated to ophthalmologists individually, to ophthalmological associations and, if necessary, to the governments with a view to their practical application. Consequently, all ophthalmologists who wish to make any observations on the conclusions in the above-named reports (to be found in the Proceedings of the XIIIth Congress, Vol. IV) are earnestly requested to address observations or comments before May 1, 1932, to the secretary of the Internat. Ophthalm. Council.

IV. The reporter on the subject "Pathological anatomy of tuberculous iridocyclitis," Prof. Dr. J. Igersheimer, requests all those who possess special preparations or sections of cases of tuberculous iridocyclitis, to forward these to his address for examination.

V. Oculists who wish to widen their professional knowledge abroad, either by a short visit to a foreign clinic, or by way of a longer stay as a volunteer, may apply to the secretary of the Internat. Ophthalm. Council, who will try to find clinics to suit them.

VI. In the year 1929, during the XIIIth Internat. Ophthalm. Congress, at Scheveningen, the Council decided to start an ophthalmological library. Most of the ophthalmological periodicals have already been collected at Leiden, where the library is established. The object is to collect there everything issued in the domain of ophthalmology. Our colleagues are therefore requested to address a reprint or copy of their publications (viz., reviews in periodicals, books, theses, etc.) to the librarian of the Internat. Ophthalm. Library, Dr. J. Kroon, Stationsweg 25, Leiden, Holland. Further particulars on the working method of this library will follow in due course.

Address : Inrichting voor Ooglijders,

Oostmolenwerf 5,

Rotterdam, Holland.

Secretary : E. MARX. 